\title{
The New Jersey Shelf Observing System
}

\author{
Scott M. Glenn, Oscar M.E. Schofield, Robert J. Chant and J. Frederick Grassle \\ Institute of Marine and Coastal Sciences \\ Rutgers University \\ New Brunswick, NJ 08901 \\ U.S.A.
}

\section{Introduction}

The coastal ocean represents up to $30 \%$ of the total global ocean productivity and more than $90 \%$ of the world's fish catch (Holigan and Reiners, 1992). The coastal ocean also represents the major chemical -"filter" between the terrestrial and open oceans with the majority of the terrestrial inputs and biological productivity being remineralized on broad shelves with little export to the continental slope (Walsh et al., 1988; Biscaye et al. 1994). This is especially important given recent evidence that human activity may be altering shelf nutrient patterns and food web structure (Hallengraeff 1993, Jorgensen \& Richardson 1996). U.S. coastal counties contain less than $20 \%$ of the landmass but over $50 \%$ of the population (CGER, 1999), with population projections exceeding $75 \%$ by 2050. Given this, it is critical to understand the fates and transport of material on the continental shelves, and to understand the potential impacts of anthropogenic pressures. This will require functional ocean observatories that combine physical/biogeochemical modeling with synoptic real-time field sampling over ecologically relevant scales (NRC Report, 2000).

The Longterm Ecosytem Observatory (LEO) (Grassle et al, 1998; Glenn et al., 2000a, Schofield et al., 2001a) serves as one prototype for the regional coastal observatories of the future. At the core of the LEO system is a cabled observatory (von Alt et al., 1997) designed to maintain a near-permanent presence on the oceanfloor. Installed offshore Tuckerton, NJ in 1996, the observatory provides power and highbandwidth two-way communications for suites of standard and guest sensors attached to a bottom-mounted junction box or "node". Archived data is available through the DODS-enabled, JAVA-based Rutgers Ocean Data Access Network (RODAN) (Zhang et al., 2001). The intensive LEO time series measurements were expanded spatially to study the physics and the biological implications of the three recurrent coastal upwelling centers that develop each summer along the southern New Jersey coast (Glenn et al., 1996). An approximately $30 \mathrm{~km} \times 30 \mathrm{~km}$ research space spanning the $3 \mathrm{~m}-30 \mathrm{~m}$ isobaths was established to completely surround the Tuckerton upwelling center. Precision earthlocation, modified cloud removal, and new compositing techniques were developed (Glenn and Crowley, 1994) and applied to the coastal satellite imagery to monitor the surface thermal evolution of the Tuckerton upwelling center. CODAR High Frequency (HF) Radar sites were established north and south of Tuckerton to provide vector surface current coverage of the upwelling centers and the associated alongshore jet (Kohut et al., 1999). To routinely acquire subsurface current and density data, Remote Environmental Measuring UnitS (REMUS) Autonomous Underwater Vehicles (AUVs) were developed (von Alt et al., 1997). The REMUS AUVs were built to carry ADCP and CTD sensor payloads a design range of $40 \mathrm{~km}-80 \mathrm{~km}$, allowing the vehicle to be deployed nearshore in the morning, fly survey lines out and back across the upwelling center, and then be 
recovered nearshore before nightfall. Real-time observatory data is posted on a website (marine.rutgers.edu/cool) that peaks at over 50,000 hits per day. This well-sampled research space was chosen as the site of an annual series of month-long Coastal Predictive Skill Experiments (CPSE) (Glenn et al., 1998) beginning in July, 1998 and ending this summer in July, 2001. Data-assimilative ocean forecasts and real-time data were used during the CPSEs to direct adaptive sampling surveys of episodic features with a fleet of coastal research vessels, AUVs and aircraft. Unlike the standard 2-D pictures of coastal upwelling, the topographically-controlled (Song et al., 2001) upwelling centers offshore southern New Jersey were found to have a repeatable 3-D structure. An anticyclonic eddy formed within the cold center, with a northward-flowing warm surface jet bending around the offshore side of the upwelling front. A previously undetected southward-flowing cold subsurface jet on the nearshore side of the upwelling eddy was observed to be rich in phytoplankton (Glenn et al., 2000a). Transport calculations reveal that the nearshore jet was capable of completely supplying all the cold water necessary to fill the upwelling center. Rather than local growth as suggested by the 2-D physical model, the high phytoplankton concentrations observed in the upwelling centers appear to be dominated by larger-scale 3-D advective processes (Schofield et al., 2001a).

Utilizing our experience in operating a local-scale coastal observatory, construction has begun on a prototype regional-scale (approximately $300 \mathrm{~km} \mathrm{x} 300 \mathrm{~km}$ ) observing system (Schofield et al., 2001b; 2001c) to characterize the physical forcing of primary productivity on the New Jersey continental shelf. Enabling technologies that facilitate construction of a modern shelf-wide observatory include: (1) a growing international constellation of high-resolution (spatial and spectral) satellites for surface thermal and near-surface ocean color charts; (2) new long-range and bistatic CODAR HF Radars that generate real-time surface current maps over distances approaching $200 \mathrm{~km}$; (3) strategically located, long-duration physical/bio-optical moorings or cabled observatories for subsurface time series at fixed locations; and (4) long-duration remotely-controlled Glider-type Autonomous Underwater Vehicles (AUVs) for mobile subsurface physical/bio-optical observations. The well-documented performance of the Bermuda Testbed Mooring (Dickey et al., 1998), the MBARI interdisciplinary moorings (Chavez et al., 1997), and the LEO cabled observatory (Grassle et al., 1998) developed and demonstrated in the 1990s have helped fuel the proliferation of these technologies into new or proposed long time-series observatories. The ability to spatially expand the time-series to the regional scale is a relatively recent capability. Progress in its implementation as part of the New Jersey Shelf Observing System (NJSOS) is described here.

\section{Science Questions}

Successful observatories are those that combine data collection efforts that address diverse science questions with real-time data distribution efforts that reach a broad spectrum of operational users. This is partially out of necessity. Operational funds to support a distributed real-time user community are scarce. Most coastal observatories still rely on a portfolio of research grants to maintain an operational status. The science questions for NJSOS cover both global and regional scales.

Global Scales. Changes in the character of the Gulf Stream may have significant impacts on northern hemisphere climate (Rossby and Gottlieb, 1998; Spall, 1996; 1997). 
Rossby and Benway (2000) found a correlation between the Gulf Stream's north-south position and shelf surface salinity that suggests lateral movements of the Gulf Stream may be caused by the time varying transport from the Scotian Shelf. Low frequency variations in Scotian shelf transport are related to wintertime temperatures (Rossby and Benway, 2000), with the highest transport following relatively warm high latitude winters. It is this high latitude winter temperature signal that climate models suggest is most sensitive to greenhouse warming (IPCC 2001). Since water properties along the North American shelf are fairly uniform between Cape Hatteras and the Scotian Shelf (Chapman et al, 1986; Chapman and Beardsley, 1989, Houghton and Fairbanks, 2000) a shelf-wide observatory along the New Jersey coast collocated with continuing long-term datasets would capture the increased transport and decreased salinity expected to occur in response to high latitude warming. Given the projected global warming trends, how will shelf circulation in the Middle Atlantic Bight be affected, how will the changes effect Gulf Stream separation at Cape Hatteras, and what are the corresponding biogeochemical impacts?

Regional Scales (<300 km). Regional issues for the New Jersey shelf center on basic questions such as what is the mean along-shelf transport and what is the physical forcing of primary productivity and the biogeochemical fluxes? Early estimates suggested the alongshelf mass transport was relatively invariant in the Middle Atlantic Bight, with offshelf transport confined to regions near Cape Hatteras at the edge of the Gulf Stream (Beardsley et al. 1976). This view changed as more recent data suggests a downshelf decrease in the alongshelf transport, implying a mean shelfwide offshore transport (Biscaye et al., 1994). Indeed, instantaneous sections across the shelf break front indicate that much of the down-shelf transport is within this region (Pickart, 2000). If the mean shelfwide offshore transport model discussed above is correct, then is the offshore transport uniform along the shelf edge? Or is it localized to bathymetric features, such as the Hudson shelf valley or the numerous canyons? This is important not only for understanding shelf physical processes but also for their potential impact on global scale carbon models (EOS 2000). How does the coastal circulation determine bulk residence time of organic material transported or produced on the shelf? How important are the localized bathymetric features in driving both surface and subsurface convergence fields and are they the major mechanism for persistent offshore biological fronts? Is the majority of organic material on the shelf remineralized (Biscayne et al. 1988, Biscaye \& Anderson 1994, Kemp 1994) or do subsurface convergence zones form "depo"-centers? What materials (and nutrients) are transported onto the shelf given that current nutrient budgets do not appear capable of supporting observed productivity rates (Biscaye et al. 1994)? This question is particularly important given increasing anthropogenic inputs associated with runoff from land, direct ocean discharges from sewage treatment, atmospheric deposition, and estuarine export (Jorgenson \& Richardson 1996, Asman \& Larsen 1996, Malone et al. 1999).

\section{New Shelf-wide Observatory Components}

The Rutgers COOL is focused on implementing a shelf-wide observatory by deploying observational systems that readily provide data for assimilation into a new generation of ocean models. The three new backbone components of the NJSOS 
represent technologies in which the proof-of-concept was demonstrated through partnerships between Rutgers scientists and private industry.

High-resolution Ocean Color Satellite Imagery. The proliferation of L-Band High Resolution Picture Transmission (HRPT) satellite data acquisition systems that began in the early 1990s have provided real-time access to the full-resolution direct-broadcast AVHRR and SeaWiFS raw datastreams to a broad range of scientific and operational users virtually anywhere in the world. Processed subsets of the data are made available to the scientific community over the Internet via systems such as the Distributed Ocean Data System (DODS). Images of derived products from the unrestricted satellites are often displayed on the World Wide Web to reach an even broader community. Rutgers has further demonstrated the utility of also acquiring data from international satellites by adding the Chinese FY1-C satellite to its existing L-Band tracking and acquisition system (Fig. 1). One advantage of the FY1-C is that it passes overhead in the late morning when summer sun angles are high but before the afternoon cumulous clouds develop. Even if the FY1-C data proves to be less accurate for scientific analyses, a second advantage is that its overflight time precedes SeaWiFS by 4 hours. Undelayed access to the FY1-C data provides scientists with the lead time to properly position their ships or AUVs in the highly variable coastal waters for the ensuing SeaWiFS overpass.
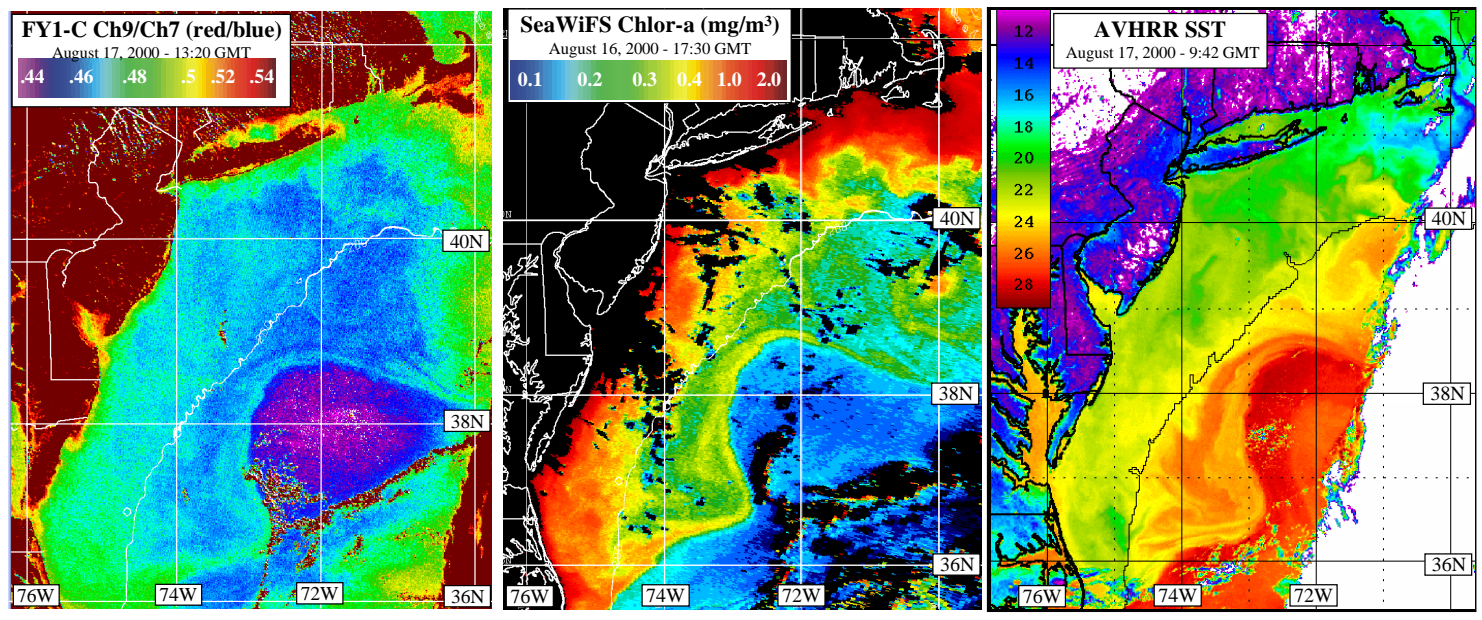

Fig. 1. FY!-C, SeaWiFS and AVHRR images of the Middle Atlantic Bight.

Real-time availability of the highest spatial and spectral resolution data from the next generation of ocean color satellites (Table 1) similarly will require regional line-ofsight access to the higher-baud X-Band direct-broadcast raw datastreams. Data recorded on-board the satellites are usually stored in a spatially degraded form before being transmitted to a centralized ground station. Data transfers therefore are delayed at least until the next overpass of this ground station. The derived data products may not be available for even longer periods of time, especially in the case of international satellites where the data delays can stretch to months. The high resolution of the satellites also results in longer revisit intervals of every other day or greater. Access to the full constellation reduces revisit intervals and opens up the possibility for coverage at different times of the same day, minimizing diurnal weather effects. For example, the afternoon cumulus clouds that compromise much of the SeaWiFS imagery along the Eastern Seaboard (Fig. 1b) can be avoided with late morning satellite passes. 
Satellite ocean color systems currently provide a suite of derived products from plant biomass, colored dissolved organic matter, sediments, inherent optical properties, primary productivity, and potentially phytoplankton community classification (Schofield et al., 1999a; Bergmann et al. 1999). New bio-optical algorithms (Schofield et al., 1999 b) are becoming available, and could be applied to other satellites in the growing constellation. The X-Band satellite data rates are large, with the size of a typical overpass measured in gigabytes rather than the 80 megabytes of a typical L-Band satellite pass. Internet-2 access will enhance the distribution of processed data to remote science teams. Similar to the existing L-Band website, selected X-Band products can be posted on the Web to benefit a broader community of real-time users. How ocean color features compare to the satellite-derived sea surface temperature fields and long-range CODARderived sea surface current fields is a topic of high scientific interest. Combined physical/bio-optical datasets will help determine if the variability is due to differences in growth (biological control) or advection (physical control).

\begin{tabular}{|c|c|c|c|c|c|c|}
\hline $\begin{array}{l}\text { Satellite/ } \\
\text { Sensor }\end{array}$ & $\begin{array}{l}\text { Country/ } \\
\text { Channels }\end{array}$ & $\begin{array}{c}\text { Data Rate } \\
(\mathrm{mps})\end{array}$ & $\begin{array}{c}\text { Delayed } \\
\text { Res. (km) }\end{array}$ & $\begin{array}{l}\text { Real-Time } \\
\text { Res. }(\mathbf{k m})\end{array}$ & $\begin{array}{l}\text { Operational/ } \\
\text { Launch }\end{array}$ & $\begin{array}{c}\text { Revisit } \\
\text { (days)/ } \\
\text { Time }\end{array}$ \\
\hline HY-1 & China & & & & & \\
\hline COCTS & 10 & 5.4 & 4 & 1 & 2001 & 2/08:30 \\
\hline CZI & 4 & & 4 & 0.25 & & 6/08:30 \\
\hline $\begin{array}{c}\text { IRS-P3 } \\
\text { MOS }\end{array}$ & $\begin{array}{c}\text { India } \\
13\end{array}$ & 5.2 & $\begin{array}{l}\text { Must be } \\
\text { turned on }\end{array}$ & 0.2 & OPL & 2-5-5days \\
\hline IRS-P4 & India & 10.4 & 1.8 & 0.36 & OPL & 2/12:00 \\
\hline OCM & 8 & & & & & \\
\hline EOS & USA & 13 & & & OPL & 2/10:30 \\
\hline MODIS & 2 & & 0.25 & 0.25 & & \\
\hline MODIS & 5 & & 0.5 & 0.5 & 2001 & 2/13:30 \\
\hline MODIS & 29 & & 1.0 & 1.0 & & \\
\hline ADEOS-2 & Japan & 6 & & & 2001 & 2/10:45 \\
\hline GLI & 6 & & 1.0 & 0.25 & & \\
\hline GLI & 30 & & 1.0 & 1.0 & & \\
\hline NEMO & USA & 150 & 0.03 & 0.03 & 2001 & 2/10:30 \\
\hline
\end{tabular}

CODAR HF Radar. Rutgers has operated a pair of $25 \mathrm{MHz}$ (40 km range) CODAR sites in the local area surrounding LEO since 1998. Raw, tidal, detided, and 30hour low-pass filtered vector current fields, along with their divergence and vorticity, are routinely calculated and displayed on the Web in near real-time. Recent results emphasize the need to measure HF-Radar antenna beam patterns to optimize system performance (Kohut et al. 2001; Paduan et al., 2001). Beam pattern measurements in "clean" environments away from buildings, utility lines, and large metal structures, indicate that the CODAR hardware is easily configured so that the measured receiver beam patterns closely match the ideal cosine and sine patterns expected for crossed loop antennas, and that the pattern shapes are constant in time. However, beam pattern measurements in "cluttered" environments can be distorted by the surrounding structures regardless of the antenna configurations. Since the local environment often cannot be modified, CODAR comparisons with the LEO ADCP data (Kohut et al., 2001) were conducted to determine if the effects of the beam pattern distortions in a cluttered environment could be minimized. The ADCP comparisons indicate that using the measured receive antenna beam patterns to determine direction optimizes system performance by improving the placement of the CODAR-derived radial current velocities in the proper directional bins. 


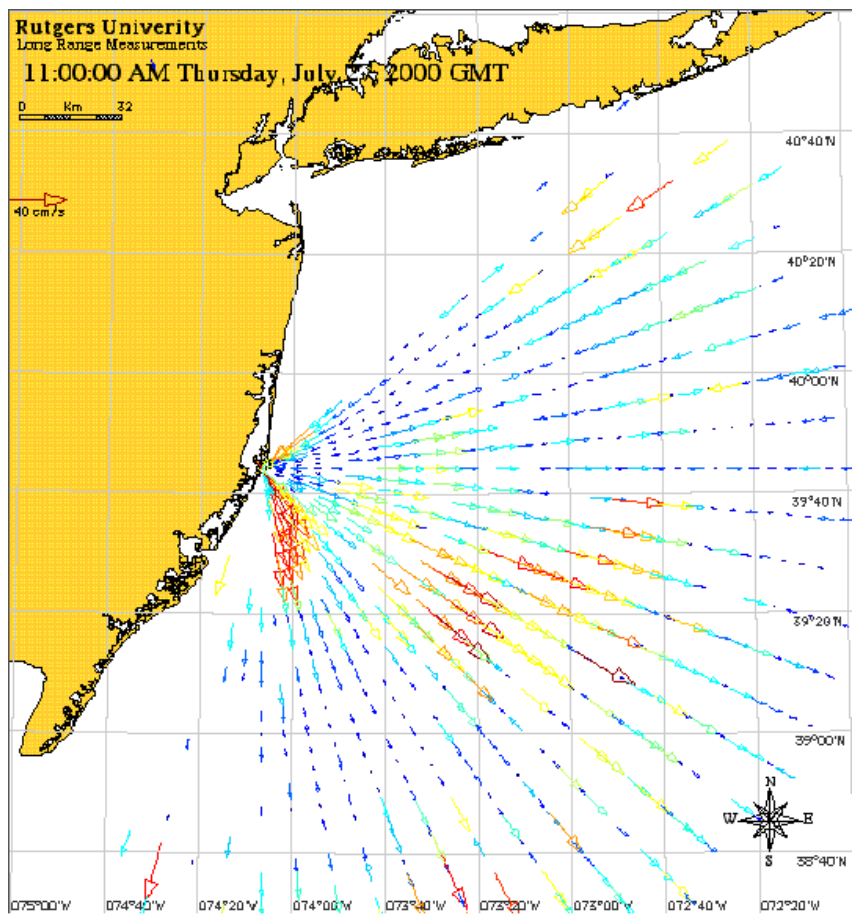

Fig. 2. Long range CODAR radial current map from Loveladies, $N J$.
A network of five longrange $(180 \mathrm{~km})$ CODAR sites for the NJSOS has already been funded. Figure 2 is a typical daytime radial current map for the first east coast long-range CODAR site located in Loveladies, New Jersey. Because of the bend in New Jersey's coastline at its midpoint, optimal coverage is achieved by focusing one pair of sites on the northern New Jersey shelf, and a second pair of sites on the southern New Jersey shelf. The fifth site will be used for (a) ongoing development and optimization tests that interrupt continuous operations, (b) filling in nearshore gaps or increasing offshore resolution in specific areas during dedicated experiments, and (c) providing a backup system in case one of the four monitoring stations goes down. Initial tests with the Loveladies long-range CODAR revealed an expected but surprisingly severe reduction in the nighttime coverage due to radio interference at some frequencies. Adding a new GPS timing unit to each long-range system will enable multiple CODARs to operate simultaneously at the best frequency for nighttime coverage.

To further increase the range of CODAR vector current coverage, especially in the nearshore direction, a proposed bistatic HF Radar (Glenn et al., 2000) is being constructed. Development of the GPS timing unit mentioned above enabled an HF Radar transmitter and receiver to be physically separated for the first time. As the separation distance increases, the constant time-delay circles of the monostatic configuration are stretched into an elliptical geometry, with the transmitter and receiver located at the two focii of the ellipse. Just as monostatic HF Radar systems measure the component of the current perpendicular to the constant delay-time circles, the bistatic CODAR measures the

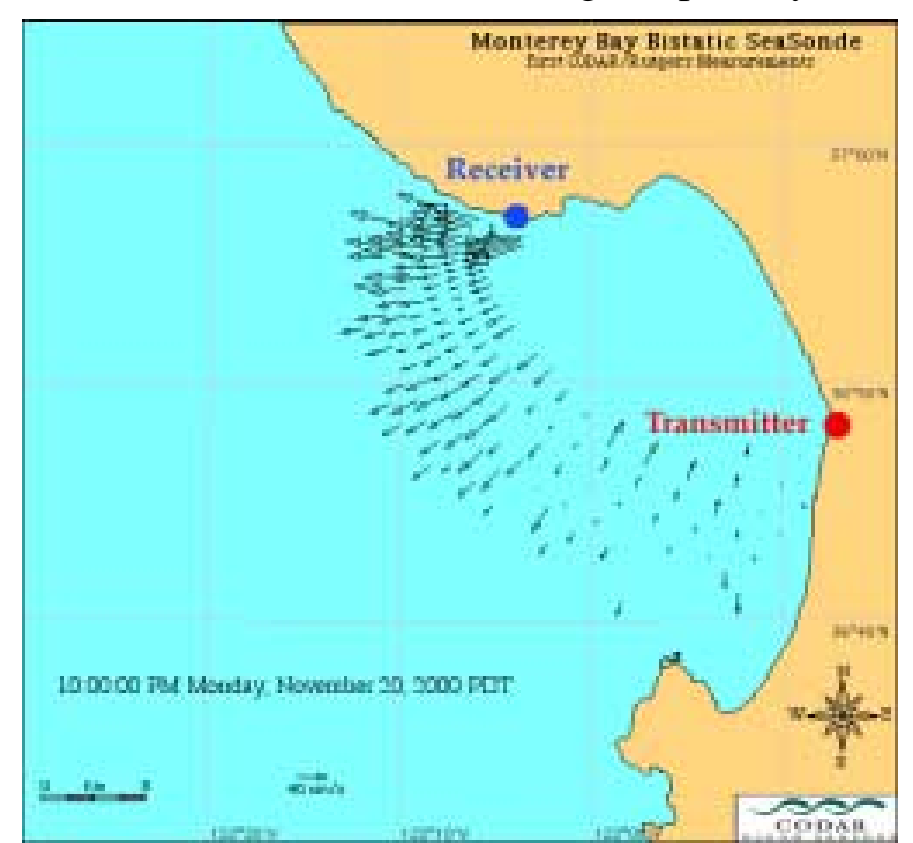

Fig. 3. Monteray Bay test of the bistatic CODAR to be deployed offshore New Jersey. 
component of the current perpendicular to the constant delay-time ellipses. The first test of the bistatic configuration was conducted at Monteray Bay (Fig. 3), with the transmitter deployed on the eastern side and the receiver on the northern side. The constant timedelay ellipses are apparent in the derived current patterns. A second test was conducted in February 2001 in which the transmitter was placed on a boat anchored offshore LEO to broadcast to the onshore receivers. The next step is to place the transmitter on a buoy that can be deployed offshore for long-durations.

Glider AUVs. Autonomous Gliders have been demonstrated in field experiments on both the east and west coasts in just the last two years. The Gliders can be programmed to patrol the subsurface for weeks at a time, surfacing to transmit their data to shore while downloading new instructions at regular intervals at a tremendous cost savings compared to traditional surface ships. The small relative cost and the ability to operate multiple vehicles with minimal personnel and infrastructure will enable small fleets of Gliders to study and map the ever-changing (in space and time) features of our subsurface coastal waters around-the-clock and calendar. The challenge ahead is to determine how best to operate a Glider fleet given cues from coupled atmosphere/ocean forecast models, from the other backbone components of a regional observation network, or from adaptive sampling platforms that include ships and other AUVs working within the regional network.

Webb Research Corporation developed the Slocum Glider AUV pictured in Fig. 4. The first untethered open ocean flight of the Slocum Glider was conducted at LEO in July 2000 (Fig. 5). The Glider's nominal mission profile consisted of a series of 2.5 minute undulations with a surfacing interval every 45 minutes. During the surface interval, a new GPS position was collected, data was transferred to shore, and new mission profiles were downloaded with a radio modem. Over the 10-day deployment period, the Glider collected and transmitted 5,190 CTD casts without ever returning to the dock. The Glider was sent on a wide variety of missions, including $20 \mathrm{~km}$ long survey lines (Fig. 6), station keeping in a 30-40 cm/sec current, undulations based on both depth and altitude, and navigation both with and without estimated current corrections. Navigational and glider control tests were aided by overlaid CODAR surface current fields to enable better glider control.

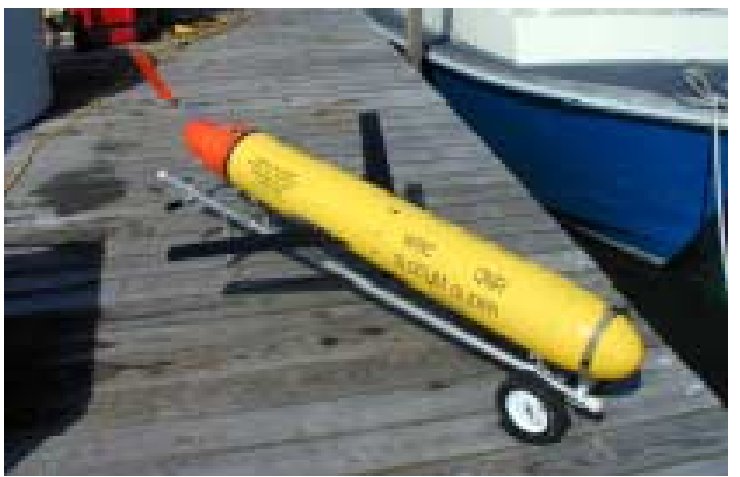

Fig. 4. Slocum Autonomous Glider

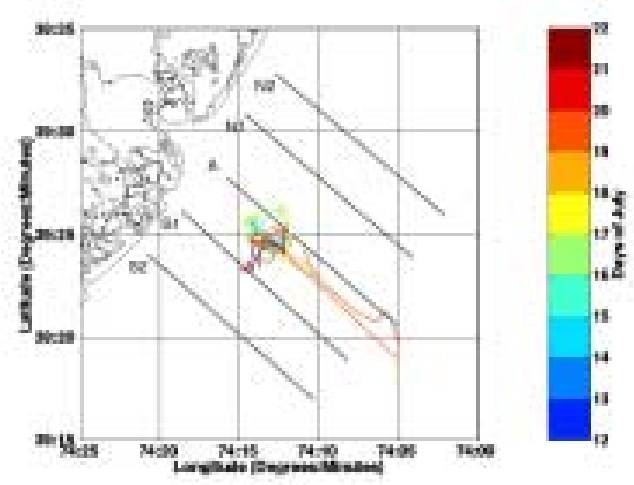

Fig. 5. Glider location during a 10 day test deployment offshore NJ in July, 2000. 
Although the first Gliders are not equipped with a current meter, their observed drift between surface intervals can be used to infer depth-averaged velocities. Gliderderived average velocity estimates are based on the differences between the actual GPS position and the expected position based on dead reckoning every time the Glider surfaces. Whenever the Glider was within $2 \mathrm{~km}$ of a LEO ADCP during the July deployment, the Glider depth time series was used to average together the corresponding ADCP velocities (Fig. 7). For comparison purposes, the top bin of the ADCP (about $3 \mathrm{~m}$ below surface) is also plotted. The RMS differences between the Glider and averaged ADCP velocities is less than the RMS differences between this ADCP and two others located $4 \mathrm{~km}$ offshore and onshore, indicating that a good part of the difference may be associated with natural variability. This opens up numerous possibilities in flight path design targeted to measure average velocities in different layers. For example, Gliders could be programmed to travel the full water column to determine the density structure, then to automatically sample the upper and lower layers individually to determine their average velocities.

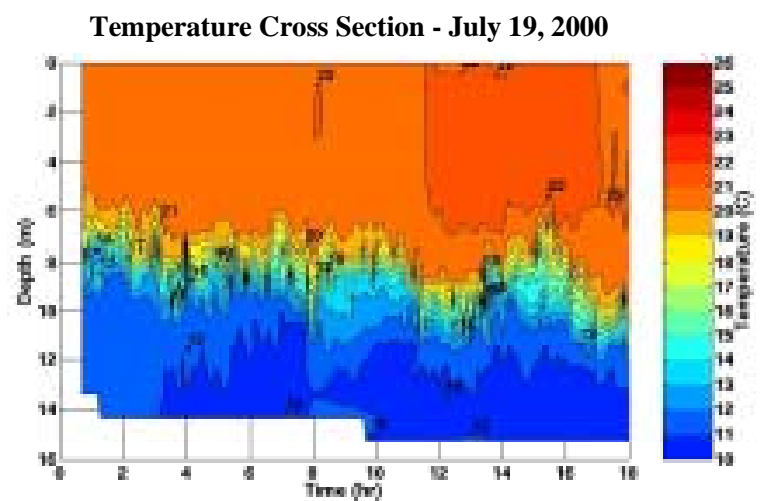

Fig. 6. Cross-shelf temperature section from the Autonomous Glider.

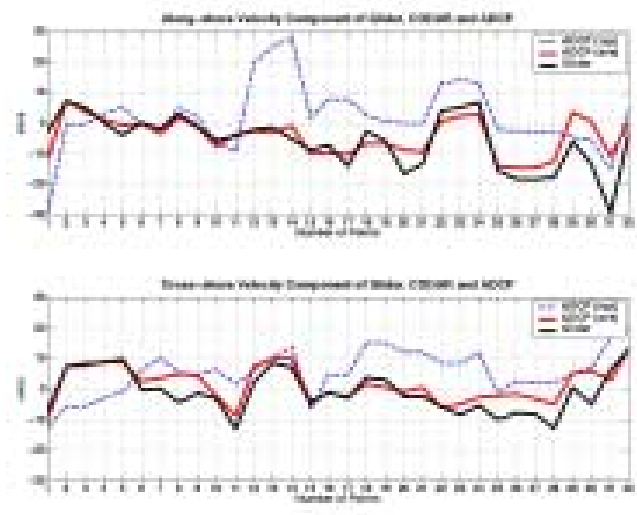

Fig. 7. Comparison of ADCP and Glider derived along shore (top) and cross shore (bottom) currents whenever the Glider was within $2 \mathrm{~km}$ of an ADCP.

\section{Conclusions}

The primary components of a regional ocean observatory for the New Jersey shelf were tested at Rutgers Long-term Ecosystem Observatory and are currently being deployed. The shelf-wide observatory is designed to address science questions ranging in scale from global to regional, from site-specific to generic. The data also provides a regional-scale well-sampled research environment in which scientists can conduct shorter, more focused and less expensive process studies. Data archives will be accessible via RODAN, and broad distribution through existing web sites (marine.rutgers.edu/cool, thecoolroom.org) will ensure that data products also reach government agencies with operational needs (U.S. Navy, U.S. Coast Guard, and NOAA), and the general public.

A cornerstone of the observatory concept is that the real-time regional data will be used in conjunction with data assimilative models, both for real-time forecast applications and for scientific hindcast studies. Long-range CODAR surface velocities provide a significant assimilation dataset (Kohut et al., 1999), but require some means to extend the CODAR data below the surface. Practical applications of many of the assimilation 
methodologies require some estimate of the seasonal pycnocline depth, since currents above the pycnocline are often well correlated with the surface, and currents below are often less correlated. Autonomous Gliders can be used to patrol the region and provide updated estimates of the pycnocline depth, but with limited resources, how can one identify the most critical regions to send the Gliders? Ensemble model runs can provide one answer (ex. Lermusiaux, 1999). Another possibility currently being investigated is the potential of high-resolution ocean color imagery to estimate pycnocline depth. The pycnocline is often associated with a local phytoplankton particle maximum and internal waves. The depth of the particle maximum will be modulated by the internal waves, and that modulation may be detectable in the spectral characteristics of the upwelling radiation. A hyperspectral satellite with the spatial resolution to resolve the internal waves may be able to detect the same modulation and back-calculate the pycnocline depth. Glider fleets could then be directed to regions required to validate the estimated depths, to determine the particle characteristics in specific areas for feedback into the optical algorithms, or to provide direct pycnocline observations in cloud covered regions.

The envisioned proliferation of coastal and global ocean observation systems, combined with the instantaneous distribution capabilities of the ubiquitous World Wide Web, will make ocean data and forecasts more widely available to universities, government agencies, industry and the general public. In response, operational oceanography is expected to grow as a profession. Some have labeled it a new profession (Mooers, 2000; Feder, 2000), while others have assured us it has existed in NOAA for nearly 200 years (Wilson and Cole, 2000) and in the Navy for over 150 years (Spinrad, 2000). The need is clear. Modern operational observatories and forecasting centers will require a new generation of operational oceanographers with skills not presently emphasized at Ph.D. granting universities (Glenn et al., 2000b). Both groups suggest that the need can be met by Masters level graduates with theoretical backgrounds in physical oceanography and engineering, and with practical training in the operation of new sensor systems, forecast models or data assimilation applications.

\section{Acknowledgments}

The Rutgers University (RU) Coastal Ocean Observation Lab (COOL) and Longterm Ecosystem Observatory (LEO) are supported by the Office of Naval Research, the National Ocean Partnership Program, the National Science Foundation, NOAA's National Undersea Research Program, and the Great State of New Jersey. Industry partners contributing to this article include SeaSpace, Inc (Robert Bernstein), CODAR Ocean Sensors (Don Barrick and Belinda Lipa), and Webb Research Corporation (Doug Webb and Clayton Jones). Contributing COOL researchers include Mike Crowley (satellites), Josh Kohut (CODAR), John Fracassi (Glider) and Sage Lictenwalner (Glider).

\section{References}

Asman W. A. H. and S. E. Larsen. 1996. Atmospheric processes. In: Eutrophication in Coastal Marine Ecosystems. B. B. Jorgenson and K. Richardson (eds). American Geophysical Union. Washington D.C. pp. 21-51.

Beardsley, R.C., W.C. Boicourt, D.V.Hansen. 1976. Physical oceanography of the Middle Atlantic Bight. In: Middle Atlantic Continental Shelf and the New York Bight, M.G. Gross, ed., American Society of Limnology and Oceanography. Special Symposium.2: 20-34. 
Bergmann, T., Schofield, O., Cullen, J., Glenn, S. Moline, M. A. 2000. Concurrence of inherent optical properties and particulate organic carbon concentrations in the Middle Atlantic Bight: Applications of ocean color imagery in coastal waters Ocean Optics SPIE.

Biscaye, P. E. and R. F. Anderson. 1994. Fluxes of particulate matter on the slope of the southern Middle Atlantic Bight: SEEP-II. Deep-Sea Research 41: 459-510.

Biscaye, P. E., R. F. Anderson and B. L. Deck. 1988. Fluxes of particles and constituents to the eastern United States continental slope and rise: SEEP-I. Continental Shelf Research 8: 855-904.

Biscaye P. E., C. N. Flagg and P. G. Falkowski. 1994. The Shelf Edge Exchange experiment, SEEP-II: an introduction to hypotheses, results and conclusions. Deep-Sea Research 41: 231-253.

Commission on Geosciences, Environment and Resources (CGER), 1999. Science for Decision Making: Coastal and Marine Geology at the U.S.Geological Survey. National Academy Press. 121 Pages.

Chapman, D.C. , J.A. Barth, R.C. Beardsley, R.G. Fairbanks. 1986. On the continuity of mean flow between the Scotian Shelf and the Middle Atlantic Bight. Journal of Physical Oceanography. 16:758-772.

Chapman. D.C., R.C. Beardsley. 1989. On the origin of shelf water in the Middle Atlantic Bight. Journal of Physical Oceanography. 19: 384-391.

Chavez, F.P., J.T. Pennington, R. Herlein, H. Jannasch, G. Thurmond and G.E. Friedrich, 1997: Moorings and drifters for real-time interdisciplinary oceanography, J. Atmos. and Ocean. Tech., 14, 11991211.

Dickey, T., D. Frye, H. Jannasch, E. Boyle, D. Manov, D. Sigurdson, J. McNeil, M. Stramska, A. Michaels, N. Nelson, D. Siegel, G. Chang, J. Wu, and A. Knap, 1998: Initial results from the Bermuda Testbed Mooring Program, Deep-Sea Res., 771-794.

Feder, Toni, 2000. Argo Begins Systematic Global Probing of the Upper Oceans. Physics Today, 53 (7), July, p. 50.

Grassle, J.F., S.M. Glenn and C. von Alt, 1998: Ocean observing systems for marine habitats. OCC '98 Proceedings, Marine Technology Society, November, 567-570.

Glenn, S.M. and M.F. Crowley, Gulf Stream and ring feature analyses for forecast model validation, J. Atmos, Oceanic Tech., 14, 1366-1378.

Glenn, S.M., M.F. Crowley, D.B. Haidvogel and Y.T. Song, 1996. Underwater observatory captures coastal upwelling events off New Jersey, Eos, transactions, American Geophysical Union, Vol. 77, June 18, pp. 233,236.

Glenn, S.M., D.B. Haidvogel, O.M.E. Schofield, J.F. Grassle, C.J. von Alt, E.R. Levine and D.C. Webb, 1998. Coastal predictive skill experiments at the LEO-15 National Littoral Laboratory. Sea Technology, 39, April, 63-69.

Glenn, S.M., W. Boicourt, B. Parker and T.D. Dickey, 2000a. Operational observation networks for ports, a large estuary and an open shelf. Oceanography, 13, 12-23.

Glenn, S.M., T.D. Dickey, B. Parker and W. Boicourt, 2000b. Long-term real-time coastal ocean observation networks. Oceanography, 13, 24-34.

Hallengraeff, G. M. 1993. A review of harmful algal blooms an their apparent global increase," Phycologia 32:79-99.

Holligan, P. M. and W. A. Reiners, 1992. Predicting the responses of the coastal zone to global change. Advanced Ecological Research 22: 211-221.

Houghton, R.W., R.G. Fairbanks. 2000. Water sources for Georges Bank. Deep-sea Research. 28:95-114.

IPCC, 2001.Intergovenmental Panel on Climate Change annual special report: The regional effects of climate change-An assessment of vulnerability. http:/www.ipcc.ch.

Ishizaka, J. 1990. Coupling of coastal zone color scanner data to a physical-biological model of southeastern U.S. continental shelf ecosystems. 3. Nutrient and phytoplankton fluxes and CZCS data assimilation. Journal Geophysical Research 95: 20,201-12.

Jorgensen, B. B. and K. Richardson. 1996. Eutrophication in Coastal Ecosystems. American Geophysical Union, Washington DC 273 pp.

Kemp, P. F. 1994. Microbial carbon utilization on the continental shelf and slope during the SEEP-II experiment. Deep-Sea Research. 41: 563-583.

Kohut, J.T., S.M. Glenn and D.E. Barrick, 1999. SeaSonde is integral to coastal flow model development. Hydro International, April, 32-35. 
Kohut, J., S.M. Glenn, and D. Barrick, 2001. Multiple HF-Radar system development for a regional Longterm Ecosystem Observatory in the New York Bight. American Meteorological Society: Fifth Symposium on Integrated Observing Systems, pp. 4-7.

Lermusiaux, P.J.F., 1999. Estimation and study of mesoscale variability in the strait of Sicily. Dyn. of Atmos. and Oceans, 29, 255-303.

MacCready, P., P.B. Rhines. 1993. Slippery bottom boundary layers on a slope. Journal of Physical Oceanography. 23:5-22.

Malone, T. C., A. Malej, L. W. Harding, N. Smodlaka, R. E. Turner. 1999. Ecosystems at the Land-Sea Margin: Drainage Basin to Coastal Sea. American Geophysical Union. Washington D.C. p. 378.

Moline, M. A., Bissett, W. P., Glenn, S., Haidvogel, D., Schofield, O. 2000. An operational multi-scale real-time long-term ecosystem observatory (LEO-15) for the coastal ocean. SPIE.

Mooers, Christopher N.K., 2000. Operational Oceanography: Shall We Dance? EOS, Transactions, American Geophysical Union, 81 (11), March 14, pp. 115-116.

National Research Council. 2000. Illuminating the Hidden Planet: The Future of Seafloor Observatory Science. National Academy Press, Washington DC pp. 135.

Paduan, J., D. Barrick, D. Fernandez, Z. Hallock and C. Teague, 2001. Improving the accuracy of coastal HF Radar current mapping, Hydro International, v. 5 , n. 1.

Pickart, R.S. 2000. Bottom boundary layer structure and detachment in the shelfbreak jet of the Middle Atlantic Bight. Journal of Physical Oceanography. 30:2668-2686.

Rossby, T., E. Gottlieb, 1998. The Oleander Project: monitoring the variability of the Gulf Stream and adjacent waters between New Jersey and Bermuda. Bulletin of the American Meteorological Society 79:5-18

Rossby, T., R.L. Benway, 2000, Slow variations in mean path of the Gulf Stream east of Cape Hatteras. Geophysical Research Letters. 27:117-120.

Schofield, O., Bergmann, T., Grzymski, J., Glenn, S. 1999a. Spectral fluorescence and inherent optical properties during upwelling events off the coast of New Jersey. SPIE Ocean Optics XIV 3: 60-67.

Schofield, O., J. Gryzmski, W. P. Bissett, G. Kirkpatrick, D. M. Millie, M. A. Moline, and C. Roesler. 1999b. Optical monitoring and forecasting systems for harmful algal blooms: Possibility or pipedream? Journal of Phycology. 35: 125-145.

Schofield, O., T. Bergmann, W. P. Bissett, F. Grassle, D. Haidvogel, J. Kohut, M. Moline and S. Glenn 2001a. The Long Term Ecosystem Observatory: An Integrated Coastal Observatory. Journal of Oceanic Engineering (submitted).

Schofield, O., Bissett, W. P., Haidvogel, D., Moline, M. A., Glenn, S. 2001b. Blueprint for a national network of coastal ocean observatories. Backscatter, submitted.

Schofield, O., Bissett, W. P., Haidvogel, D., Moline, M. A., Glenn, S. 2001c. Integrated coastal ocean observatories. Transactions of the Institute of Electrical and Electronics Engineers. submitted.

Song, T., D.B. Haidvogel and S.M. Glenn, 2001. Effects of topography variability on the formation of upwelling centers off New Jersey: A simple theoretical model, Journal of Geophysical Research, submitted.

Spall, M. A. 1997. Dynamics of the Gulf Stream/Deep western boundary current crossover. Part II entrainment and recirculation. . Journal of Physical Oceanography. 27:1054-1071

Spall, M. A. 1996. Dynamics of the Gulf Stream/Deep western boundary current crossover. Part I lowfrequency internal oscillations. Journal of Physical Oceanography. 26:2169-2168

Spinrad, Richard W., 2000. Comment on Operational Oceanography: Shall We Dance? EOS, Transactions, American Geophysical Union, 81 (26), June 27, p. 294.

von Alt, C.J., M.P. De Luca, S.M. Glenn, J.F. Grassle and D.B. Haidvogel, 1997: LEO-15: Monitoring \& managing coastal resources. Sea Technology, 38, (8), pp. 10-16

Walsh, J. J., P. E. Biscaye and G. T. Csanady. 1988. The 1983-1984 Shelf Edge Exchange Processes (SEEP)-I experiment: hypotheses and highlights. Continental Shelf Research 8: 435-456.

Wilson, Stan and Muriel Cole, 2000. Comment on "Operational Oceanography: Shall We Dance?" EOS, Transactions, American Geophysical Union, 81 (47), November 21, p. 564.

Zhang, Yunqing P., John F. Fracassi, John E. Wiggins, Scott M. Glenn and J. F. Grassle, 2001. RODAN: Rutgers Ocean Data Access Network Powered by Java Technologies. American Meteorological Society: Fifth Symposium on Integrated Observing Systems, pp. 21-25. 